
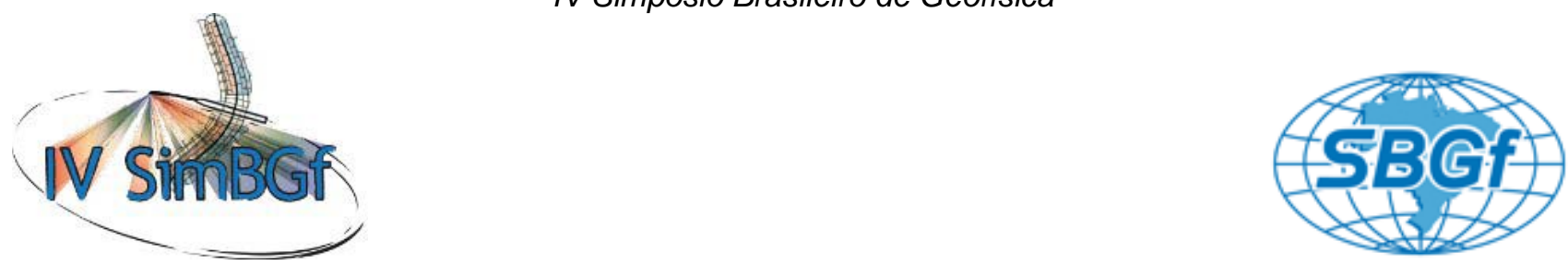

\title{
Aplicação de dados aerogeofísicos na análise estrutural do corpo São Tiago, borda meridional do Cráton São Francisco
}

Luiz Paulo Beghelli Junior, UnB; Catarina L. Benfica Toledo, UnB; Adalene Moreira Silva, UnB; Peter Christian Hackspacher, UNESP.

Copyright 2010, SBGf - Sociedade Brasileira de Geofísica

Este texto foi preparado para a apresentação no IV Simpósio Brasileiro de Geofísica Brasília, 14 a 17 de novembro de 2010. Seu conteúdo foi revisado pelo Comitê Técnico do IV SimBGf, mas não necessariamente representa a opinião da SBGf ou de seus associados. É proibida a reprodução total ou parcial deste material para propósitos comerciais sem prévia autorização da SBGf.

\section{Resumo}

A aerogeofísica de alta resolução ressaltou a existência de um corpo gnáissico na região de São Tiago (MG), próximo ao Lineamento Jeceaba-Bom Sucesso, limite entre os terrenos arqueanos e paleoproterozóicos (Cinturão Mineiro). Este corpo era considerado como integrante dos terrenos paleoproterozóicos. Entretanto, dados recentes indicam uma evolução estrutural mais complexa que os demais pertencentes ao Cinturão Mineiro. A deformação heterogênea atuante foi processada em diferentes níveis crustais e em três fases distintas de deformação. O padrão estrutural observado no corpo São Tiago é semelhante ao dos terrenos arqueanos, com redobramentos que não são encontrados nos corpos paleoproterozóicos.

\section{Introdução}

A borda meridional do Cráton São Francisco (CSFM) é caracterizada por aglomerações neoarqueanas de terrenos policíclicos estabilizadas em $2.6 \mathrm{Ga}$ (Noce et al., 1998). Esta plataforma neoarqueana estabilizada teve suas bordas retrabalhadas pelos eventos proterozóicos Transamazônico e Brasiliano (Teixeira et al., 2000). Os terrenos referentes ao retrabalhamento da plataforma durante o Evento Transamazônico compõem o Cinturão Mineiro (Teixeira, 1985; Alkmin et al., 2004).Estas unidades são parcialmente cobertas por rochas sedimentares neoproterozóicas do Supergrupo São Francisco e estão envolvidas pelas faixas de dobramentos Brasília Meridional, Ribeira e Araçuaí, formadas durante a orogenia neoproterozóica Brasiliano/Pan Africana (Figura 1).

Os levantamentos aerogeofísicos de alta resolução realizado no Estado de Minas Gerais têm auxiliado no entendimento da evolução tectônica e no estabelecimento preciso dos limites do Cráton São Francisco (Figura 1). As imagens gamaespectrométricas e magnetométricas fornecem informações importantes a respeito da assembleia tectônica do CSFM e adjacências, realçando os limites e a estruturação interna dos diferentes domínios tectônicos (Silva et al., 2003). Entre as feições identificadas está um domo gnáissico de forma arredondada e com $220 \mathrm{~km}^{2}$ de área na região da cidade de São Tiago, no sul de Minas Gerais. Este corpo, denominado por Corpo São Tiago, está localizado no limite entre terrenos arqueanos e paleoproterozóicos (Cinturão Mineiro), no extremo sul do Cráton São Francisco, próximo ao Lineamento Jeceaba-Bom Sucesso.

Trabalhos de campo realizados recentemente na região de São Tiago detectaram evidências de uma evolução marcada pela superposição de diferentes eventos termotectônicos na porção interna e externa do domo, diferenciando-o dos demais corpos plutônicos de idades paleoproterozóicas associados ao Cinturão Mineiro. O padrão estrutural do corpo São Tiago, observado em campo e nas imagens aerogeofísicas, é semelhante ao padrão estrutural observado nos terrenos gnáissicos arqueanos localizados a NNW do corpo.

Neste trabalho, os dados aerogeofísicos de alta densidade de amostragem foram utilizados para auxiliar na análise estrutural do domo são Tiago, a partir da identificação e caracterização das estruturas tectônicas presentes no domo e em suas encaixantes. A integração dos dados aerogeofísicos e geológicos contribuíram para o entendimento dos processos de colocação e deformação do Corpo São Tiago, bem como para o estudo de suas relações estratigráficas com as demais unidades geológicas da região.

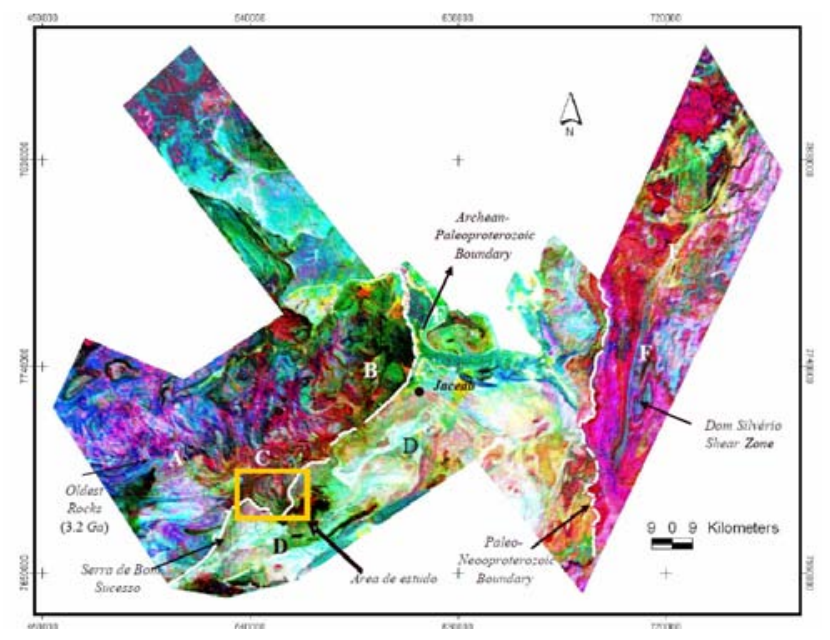

Figura 1 - Imagem gamaespectrométrica K-eTh-eU em falsa cor CMY do Projeto Pitangui-São João del ReiIpatinga (Silva et al., 2003). (A) Complexo Campo Belo, (B) Complexo Bonfim, (C) Complexo Passa Tempo, (D) Domínio do Cinturão Minério, (QF) Quadrilátero Ferrífero e (F) Faixa Araçuaí. 


\section{Métodos}

Os dados aerogeofísicos utilizados nesta pesquisa fazem parte do Projeto Pitangui-São João Del Rey-Ipatinga (Área 2), promovido pela Companhia de Desenvolvimento Econômico de Minas Gerais (CODEMIG) em 2001. Neste projeto, os perfis gamaespectrométricos e magnetométricos foram efetuados com sobrevoo a $100 \mathrm{~m}$ de altitude, com linhas espaçadas de $250 \mathrm{~m}$ e linhas de controle a cada $2.500 \mathrm{~m}$. O levantamento foi realizado em dois blocos distintos com diferentes direções de voo e de linhas de controle, visando à obtenção dos dados perpendiculares às principais estruturas da área (Lasa, 2001).

Os dados desse projeto foram processados pela empresa Lasa, reprocessados segundo os procedimentos de Silva et. al., (2003) e recortados para a área de estudo utilizando o software Geosoft-Oasis Montaj 5.1.8. Os produtos derivados do campo magnético anômalo (Amplitude do Sinal Analítico, Amplitude do Gradiente Horizontal Total, Dx, Dy e Dz) foram utilizados na interpretação de domínios e feições estruturais. As composições falsa-cor ternárias RGB e CMY, geradas a partir dos respectivos canais de $\mathrm{K}$, eTh e eU, foram utilizadas na definição de domínios com assinaturas gamaespectrométricas semelhantes e, posteriormente, classificadas para a elaboração do mapa litogeofísico (Figura 2). Para auxiliar na interpretação da imagem gamaespectrométrica, foi aplicada a técnica de Classificação Não-Supervisionada, utilizando o software Envi 4.4. Após vários testes com diferentes classes e interações, a imagem produzida pelo método ISODATA com 10 classes e 10 interações foi a que delineou melhor as diferentes estruturas e domínios.

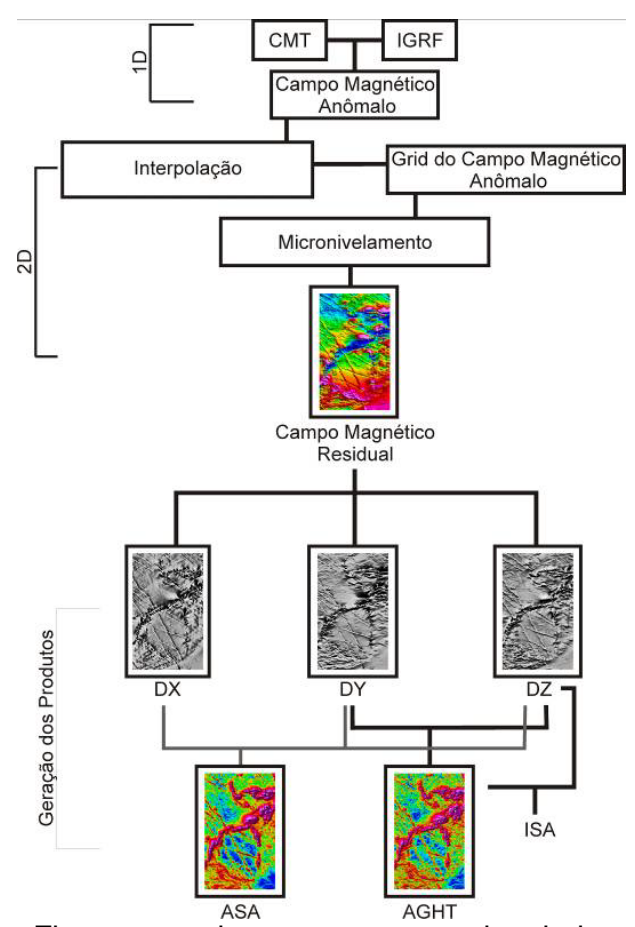

Os produtos aerogeofísicos obtidos foram colocados à prova durante as atividades de campo com o intuito de validá-los, observando-se a ocorrência ou não de lineamentos, bem como os elementos estruturais na escala de afloramento, elementos estes que foram previamente identificados nos produtos. Por fim, foram caracterizados diferentes domínios litológicos.

\section{Resultados}

A análise dos produtos magnéticos e gamaespectrométricos permitiu a identificação de um corpo de formato aproximadamente ovoide, margeado por unidade(s) de alto $\mathrm{K}$, eTh e eU e de alta susceptibilidade magnética. Sua porção interna é constituída por diferentes domínios gamaespectrométricos dobrados e redobrados, possui baixo magnético e é cortada por dois conjuntos de diques de direção NW. As rochas adjacentes se amoldam ao corpo e suas estruturações internas acompanham a cinemática da zona de cisalhamento Jeceaba-Bom Sucesso. A este corpo identificado foi dado o nome de São Tiago (Figura 3).

Este corpo é delimitado na porção sul pelas rochas da Faixa Rio das Mortes do Greenstone Belt Barbacena e pelo Tonalito Tabuões. À sudeste, o corpo é cortado por apófises do granito Ritápolis. As bordas oeste, noroeste e norte deste corpo estão em contato com porções descontínuas de uma sequencia caracterizada por formações ferríferas intercaladas com xistos. A sequência em questão é correlata ao Supergrupo Minas, que é bem caracterizada nas imagens magnetométricas, embora não aflore de maneira contínua, como pode ser visualizado na imagem ternária K-eTh-eU RGB. Enxames de diques de direção NW atravessam o corpo São Tiago.

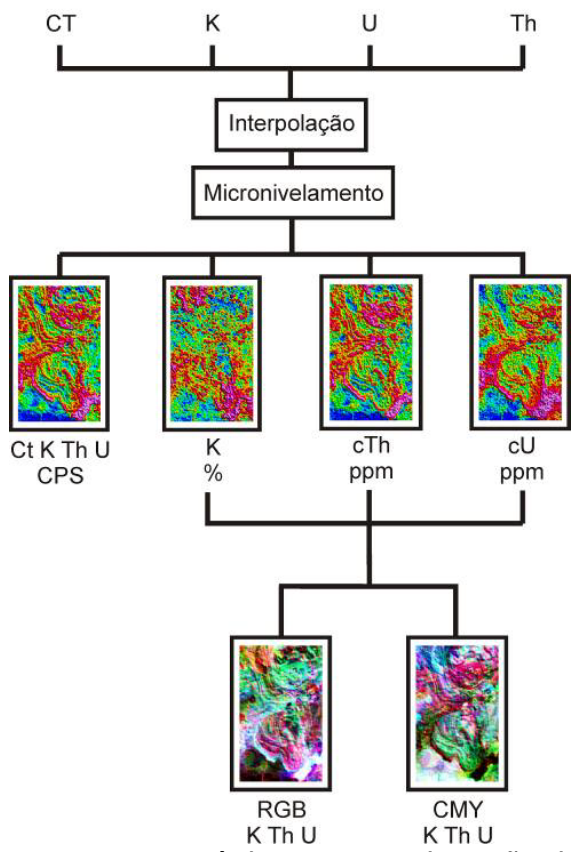

Figura 2 - Fluxograma do processamento dos dados magnetométricos e gamaespectrométricos para a obtenção dos seus respectivos produtos aerogeofísicos. 
A borda do corpo São Tiago apresenta composição sienogranítica e monzogranítica enquanto que, seu interior é caracterizado por ortognaisses tonalíticos com bandamentos milimétricos a decimétricos e por dobras isoclinais, ambos apresentando estruturas migmatíticas. Pode se notar em campo as relações de contato entre ambos os tipos, onde as porções graníticas, mais novas, ocorrem como bolsões ou como camadas de baixo ângulo e cortam o bandamento gnáissico. Estas porções graníticas também são intrusivas nas demais encaixantes, como nas rochas máficas do greenstone belt Barbacena, no tonalito Tabuões e ainda nas Rochas do Super Grupo Minas.

Na porção interna do corpo São Tiago há estruturas dúcteis mais antigas mostrando padrão de redobramento. Tais estruturas incluem bandamento gnáissico, foliações espaçadas, lineações minerais de estiramento, zonas de cisalhamento de baixo ângulo e dobramentos isoclinais. Com base em critérios de corte e superposição de estruturas, campo de tensões e níveis crustais de geração das mesmas, foram definidas três fases de deformação para a região do corpo São Tiago e adjacências, aqui designadas de Dn-1, Dn e Dn+1.

A fase $D_{n-1}$, mais antiga, está restrita a porção central do Corpo São Tiago e compreende o bandamento gnáissico $\left(\mathrm{S}_{\mathrm{n}-1}\right)$ e dobramentos isoclinais $\left(\mathrm{F}_{\mathrm{n}-1}\right)$, ambos desenvolvidos em condições de fácies anfibolito superior sob caráter progressivo. A segunda fase $\left(D_{n}\right)$ gerou as feições estruturais penetrativas da área, impressa no corpo e em suas encaixantes. O evento Dn compreende zonas de cisalhamento, foliação milonítica, lineação de estiramento mineral, dobras $F_{n}$ e foliação de baixo ângulo. Os limites do São Tiago são estabelecidos por zonas de cisalhamento transcorrentes de regime dúctil a dúctil-rúptil, o que demonstra a profundidade em que estas foram formadas. Estas zonas iniciaram 0 soerguimento mecânico do corpo São Tiago. O soerguimento pode ser indicado pela foliação de baixo ângulo restrita somente a este corpo, diferenciando-o tectonicamente das unidades vizinhas. Por último, a fase Dn+1 representa zonas de cisalhamento extensionais, falhas e fraturas de regime rúptil, dúctil-rúptil. Essas estruturas seriam indicadores finais do evento extensional que permitiu o soerguimento final do São Tiago. Essas zonas de cisalhamento extensionais e falhas normais ocorrem principalmente ao longo do lineamento Bom Sucesso (Coelho et al., em preparação), cortando a sequência do Supergrupo Minas, nas margens do corpo São Tiago.

\section{Discussão e Conclusões}

O conhecimento geológico disponível sobre as proximidades da cidade de São Tiago são os dados publicados por Silva et al., (2002) e Campos (2004), que se resumem, principalmente, em dados de análises isotópicas $\mathrm{U}-\mathrm{Pb}$ e análises geoquímicas. Silva et al., (2002) identificaram um granodiorito gnáissico foliado com xenólitos das rochas hospedeiras, que são os ortognaisses do embasamento arqueano. A idade de cristalização magmática $\mathrm{U}-\mathrm{Pb}$ para o granodiorito gnáissico de São Tiago é $2.050 \pm 12$ Ma. Campos (2004), por sua vez, identificou a Suíte Ígnea São Tiago, a qual engloba, entre outros, o Granodiorito/Trondhjemito São Tiago, com idade de cristalização U-Pb de1.887 + $19 \mathrm{Ma}$.

Projetando-se em mapa os pontos referentes às amostras dos autores citados sobre a imagem aerogamaespectrométrica e o mapa geológico do corpo São Tiago e proximidades, observou-se que as amostras seriam correspondentes à borda e aos terrenos à leste do corpo São Tiago, e não propriamente ao corpo São Tiago. Desta forma, as idades obtidas não representam a evolução isotópica do corpo São Tiago. Além do mais, o padrão de dobramento do corpo São Tiago, identificado e discutido neste projeto, indica evolução semelhante à evolução dos terrenos arqueanos, distinguindo-o dos corpos plutônicos paleoproterozóicos.

As análises isotópicas U-Pb e Sm-Nd obtidas no âmbito deste projeto para o corpo São Tiago, resultaram em idades de cristalização iguais a $2.667 \pm 43$ Ma e $2.701 \pm$ $38 \mathrm{Ma}$. As idades de extração mantélica do materialfonte, $\mathrm{T}_{\mathrm{DM}}$, que originou as rochas do corpo São Tiago foram 3,14 e 3,26 . Os respectivos valores de $\varepsilon_{\mathrm{Nd}(\mathrm{T})}$ foram -2.65 e -3.01

Tais análises isotópicas corroboram a suspeita que o São Tiago tem história evolutiva distinta daquela até então conhecida. Suspeita essa que teve início na interpretação dos produtos aerogeofísicos da região, os quais foram validados pelas relações de campo e pelas análises estruturais deste projeto. Diante desta constatação e da questão de como rochas arqueanas foram colocadas em meio às rochas paleoproterozóicas, foram aventadas algumas hipóteses de evolução tectônica para o corpo São Tiago. Estas hipóteses envolveriam a colocação mecânica deste corpo durante a colisão transamazônica, não envolvendo processos intrusivos.

Inicialmente, o grupo de corpos plutônicos paleoproterozóicos ao qual o corpo São Tiago era relacionado, não possui a fase de deformação Dn-1. Esta fase compreende o bandamento gnáissico e dobramentos isoclinais, provavelmente gerados durante o Neoarqueano tardio. Ambas as estruturas foram desenvolvidas em fácies anfibolito superior e estão restritas ao corpo São Tiago, facilmente identificadas na imagem gamaespectrométrica e no produto da classificação não-supervisionada. A fase seguinte, Dn, associada ao Evento Transamazônico, correspondem às zonas de cisalhamento transcorrentes que iniciaram o soerguimento mecânico do corpo São Tiago. O Lineamento Jeceaba-Bom Sucesso está bem destacado nos produtos da magnetometria pela alta susceptibilidade magnética, padrão decorrente da sua natureza de zona de cisalhamento transcorrente e pela continuidade dos itabiritos da Formação Cauê. A foliação de baixo ângulo Sn que é restrita ao corpo São Tiago, indica a descompressão que acompanhou o início do soerguimento mecânico do corpo. Possivelmente a descompressão gerada na fase extensional $D n+1$, causada pelo abatimento do orógeno, promoveu a fusão e geração das auréolas de rochas graníticas de alto KeTh-eU existentes em torno do corpo e explicaria a 
origem "alóctone" do São Tiago em relação aos demais. Essa fase também seria a responsável pela colocação dos diques que cortam o São Tiago, como identificados nas imagens magnetométricas.

A idade paleoproterozóica apresentada por Silva et al., (2002) corresponderia, portanto, às auréolas de rochas graníticas de alto K-eTh-eU das bordas do São Tiago. A origem dessa "auréola" seria o soerguimento do corpo São Tiago durante o evento Transamazônico, com refusão de suas bordas, ou, seria a colocação do Granitóide Ritápolis a leste, onde esse material mais novo aproveitaria as descontinuidades físicas das bordas do corpo alóctone São Tiago para se alojar. A idade, também paleoproterozóica, obtida por Campos (2004) deve pertencer a uma terceira unidade à leste, entre o Granito Ritápolis e o corpo São Tiago.Finalmente, o corpo São Tiago teria sido deformado e submetido ao metamorfismo de fácies xisto verde durante o Evento Brasiliano, comprovado pelos interceptos inferiores das discórdias apresentadas neste projeto.

\section{Agradecimentos}

Os autores agradecem a FAPESP auxilia pesquisa processo: 2006/51931-0 pelo financiamento dos trabalhos de campo, confecção das laminas delgadas e análises isotópicas. Ao Professor Mássimo Matteini (UFOP) pelo auxílio no tratamento dos dados das análises isotópicas e à equipe do Laboratório de Geocronologia da Universidade de Brasília pelo suporte na preparação e nas análises das amostras.

\section{Referências}

Alkmin, F.F., 2004. O que faz de um Cráton um Cráton? O Cráton São Francisco e as revelações Almeidianas ao delimitá-lo. In: Mantesso-Neto, V.; Bartorelli, A.; Carneiro, C.D.R; Brito-Neves, B.B. (orgs). In: Geologia do Continente Sul-Americano: Evolução da obra de Fernando Flávio Marques de Almeida. Sp, p.17-35.

Campos, J. C. S. 2004. O Lineamento Jeceaba-Bom Sucesso como Limite dos Terrenos Arqueanos e Paleoproterozóicos do Cráton São Francisco Meridional: Evidências Geológicas, Geoquímicas (Rocha Total) e Geocronológicas $(U-P b)$. Tese de Doutoramento, Departamento de Geologia da Escola de Minas, Universidade Federal de Ouro Preto, 191p.

Coelho F.S., Araujo S.A., Toledo C.L.B., Silva A.S., Hackspacher P. C. (Em preparação). Análise Estrutural da Serra de Bom Sucesso e suas implicações para a evolução da Borda Meridional do Cráton São Francisco.

Lasa, 2001. Lasa Engenharia e Prospecções S.A., Relatório final do levantamento e processamento dos dados magnetométricos e gamaespectrométricos. Levantamento Aerogeofísico de Minas Gerais, Área 2. Projeto Pitangui - São João Del Rey - Ipatinga. Volume I, Texto técnico.

Noce C.M., Machado N., Teixeira W. 1998. U-Pb geochronology of gneisses and granitoids in the
Quadrilátero Ferrífero (southern São Francisco cráton): age constraints for Archean and Paleoproterozoic magmatismo and metamorphism. Revista Brasileira de Geociências, 28: 95-102.

Silva, L.C., Armstrong, R., Noce, C.M., Carneiro, M.A., Pimentel, M., Pedrosa-Soares, A.C., Leite, C.A., Vieira, V.S., Silva, M.A., Paes V.J.C., Cardoso Filho, J.M. 2002. Reavaliação da evolução geológica em terrenos Précambrianos brasileiros com base em novos dados U-Pb SHRIMP, parte II: Orógeno Araçuaí, Cinturão Mineiro e Cráton São Francisco Meridional. Revista Brasileira de Geociências, 32: 161-176.

Silva, A.M., Filho, C.R.S., Toledo, C.L.B., Dantas, E.L. 2003. Amalgamation of different crustal blocks in the Southernmost Part of the São Francisco Craton constrained by airborne geophysical data, Brazil. In: $8^{\mathrm{TH}}$ International Congress of the Brazilian Geophysical Society, Rio de Janeiro, Brazil.

Teixeira, W. 1985. A evolução tectônica da porção meridional do cráton do São Francisco com base em interpretações geocronológicas. Instituto de Geociências da Universidade de São Paulo, São Paulo, Tese de Doutorado, 207 p.

Teixeira W., Sabaeté J.P., Barbosa J., Noce C.M., Carneiro A.M. 2000. Archean and Paleoproterozoic tectonic evolution of the São Francisco Craton. In: U. Cordani, E. Milani, A. Thomas Filho, D.A. Campos (eds.) Tectonic Evolution of South America, $31^{\text {st }}$ Intern. Geol. Congr., Rio de Janeiro, p. 101-138. 

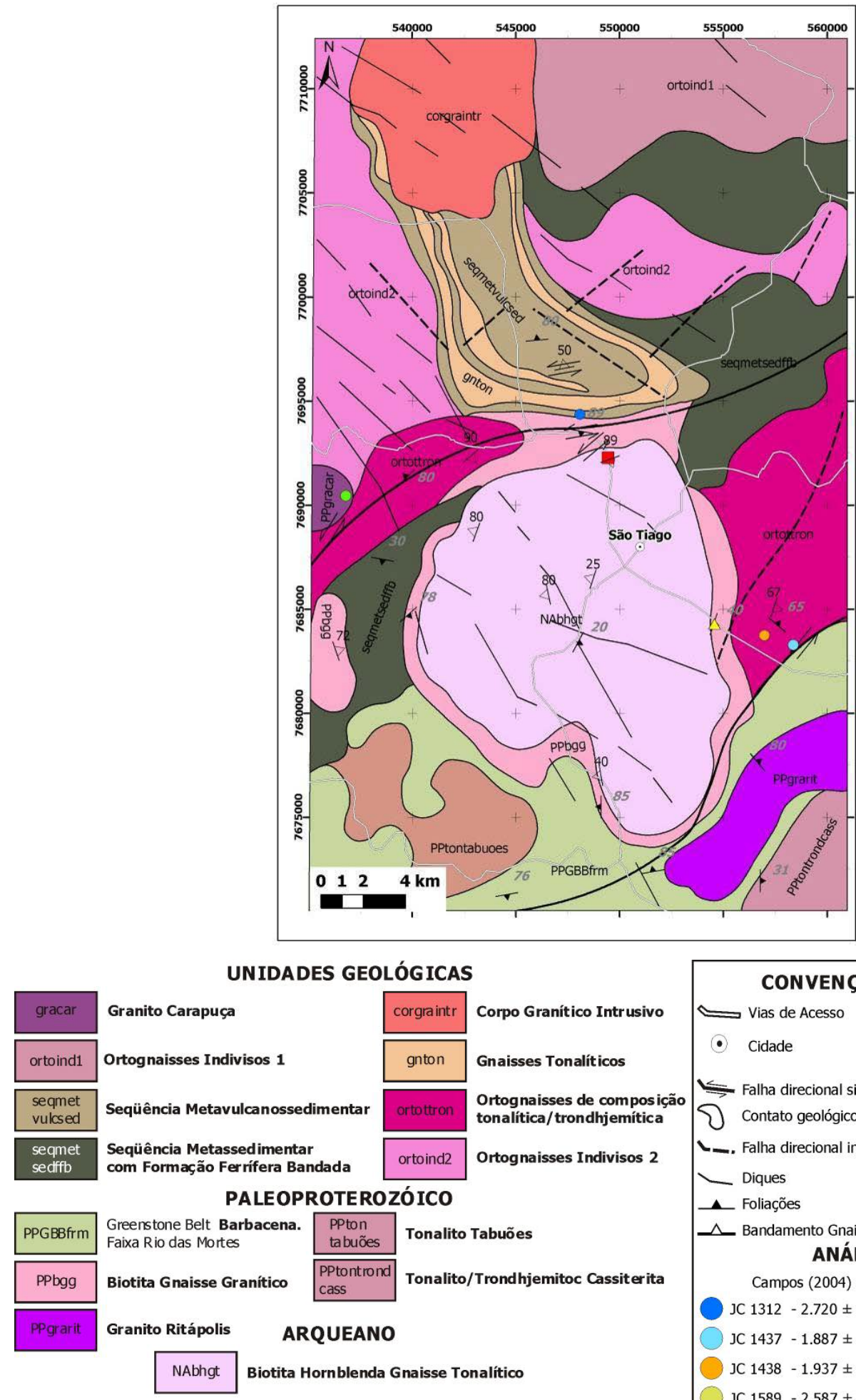

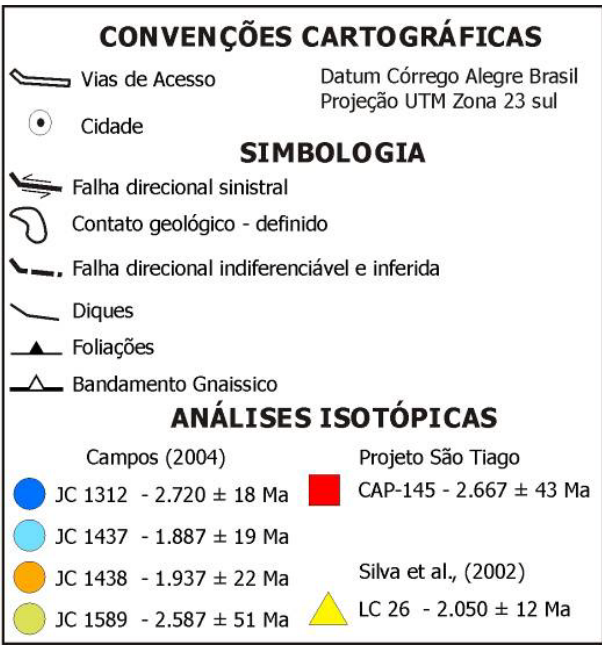

Figura 3 - Mapa geológico do corpo São Tiago e proximidades. 